\title{
The Danish Prostate Cancer Database
}

This article was published in the following Dove Press journal:

Clinical Epidemiology

25 October 2016

Number of times this article has been viewed

\section{Mary Nguyen-Nielsen ${ }^{1,2}$ \\ Søren Høyer ${ }^{3}$ \\ Søren Friis ${ }^{4}$ \\ Steinbjørn Hansen ${ }^{5}$ \\ Klaus Brasso ${ }^{6}$ \\ Erik Breth Jakobsen ${ }^{7}$ \\ Mette $\mathrm{Moe}^{8}$ \\ Heidi Larsson ${ }^{9}$ \\ Mette Søgaard 9 \\ Anne Nakano 9,10 \\ Michael Borre'}

'Department of Urology, Aarhus University Hospital, Aarhus, ${ }^{2}$ Diet,

Genes and Environment, Danish

Cancer Society Research Center,

Copenhagen, ${ }^{3}$ Department of Pathology, Aarhus University Hospital,

Aarhus, ${ }^{4}$ Danish Cancer Society

Research Centre, Danish Cancer

Society, Copenhagen, ${ }^{5}$ Department of

Oncology, Odense University Hospital,

Odense, ${ }^{6}$ Copenhagen Prostate

Cancer Center and Department of

Urology, Rigshospitalet, University

of Copenhagen, Copenhagen,

${ }^{7}$ Department of Urology, Næstved

Hospital, Næstved, ${ }^{8}$ Department of

Oncology, Aalborg University Hospital,

Aalborg, ${ }^{9}$ Department of Clinical

Epidemiology, Aarhus University

Hospital, ${ }^{10} \mathrm{Competence} \mathrm{Centre}$

for Health Quality and Informatics

(KCKS-Vest), Aarhus, Denmark
Correspondence: Mary Nguyen-Nielsen Department of Urology, Aarhus University Hospital, Palle Juul-Jensens Boulevard 99, 8200 Aarhus, Denmark Email maryniel@rm.dk
Aim of database: The Danish Prostate Cancer Database (DAPROCAdata) is a nationwide clinical cancer database that has prospectively collected data on patients with incident prostate cancer in Denmark since February 2010. The overall aim of the DAPROCAdata is to improve the quality of prostate cancer care in Denmark by systematically collecting key clinical variables for the purposes of health care monitoring, quality improvement, and research.

Study population: All Danish patients with histologically verified prostate cancer are included in the DAPROCAdata.

Main variables: The DAPROCAdata registers clinical data and selected characteristics for patients with prostate cancer at diagnosis. Data are collected from the linkage of nationwide health registries and supplemented with online registration of key clinical variables by treating physicians at urological and oncological departments. Main variables include Gleason scores, cancer staging, prostate-specific antigen values, and therapeutic measures (active surveillance, surgery, radiotherapy, endocrine therapy, and chemotherapy).

Descriptive data: In total, 22,332 patients with prostate cancer were registered in DAPROCAdata as of April 2015. A key feature of DAPROCAdata is the routine collection of patient-reported outcome measures (PROM), including data on quality-of-life (pain levels, physical activity, sexual function, depression, urine and fecal incontinence) and lifestyle factors (smoking, alcohol consumption, and body mass index). PROM data are derived from questionnaires distributed at diagnosis and at 1-year and 3-year follow-up. Hitherto, the PROM data have been limited by low completeness (26\% among newly diagnosed patients in 2014).

Conclusion: DAPROCAdata is a comprehensive, yet still young clinical database. Efforts to improve data collection, data validity, and completeness are ongoing and of high priority.

Keywords: prostate cancer, clinical quality indicators, database research

\section{Introduction}

The Danish Prostate Cancer Database (DAPROCAdata) is a nationwide clinical cancer database that prospectively collects data on key clinical parameters for prostate cancer (Table 1). DAPROCAdata is closely affiliated with the national expert group, the Danish Prostate Cancer Group (DAPROCA), which consists of clinicians and scientists responsible for developing and maintaining national clinical guidelines for the treatment of prostate cancer in Denmark. ${ }^{1}$

\section{Aim of database}

The overall aim of DAPROCAdata and the DAPROCA expert group is to improve the quality of care and management of patients with prostate cancer in Denmark. More 
Table I Overview of the DAPROCAdata

\begin{tabular}{|c|c|c|}
\hline \multicolumn{3}{|l|}{ General information } \\
\hline $\begin{array}{l}\text { Patient } \\
\text { population }\end{array}$ & $\begin{array}{l}\text { Incident prostate } \\
\text { cancer }\end{array}$ & $\begin{array}{l}\text { Data collection since } \\
\text { February } 2010\end{array}$ \\
\hline Data coverage & Nationwide & $\begin{array}{l}22 \text { urological and oncological } \\
\text { departments participating in } \\
\text { data registration }\end{array}$ \\
\hline Data collection & Continuous & $\begin{array}{l}\text { Data linkage from central } \\
\text { registries combined with } \\
\text { online prospective data } \\
\text { collection of key clinical } \\
\text { variables by treating clinicians }\end{array}$ \\
\hline $\begin{array}{l}\text { Clinical quality } \\
\text { indicators }\end{array}$ & $N=10$ & \\
\hline Clinical data & Diagnosis Clinical & Data Registration Form \\
\hline registration forms & $\begin{array}{l}\text { Urology Clinical D } \\
\text { Oncology Clinical }\end{array}$ & $\begin{array}{l}\text { ata Registration Form } \\
\text { Data Registration Form }\end{array}$ \\
\hline PROM questionnaires & $\begin{array}{l}\text { Data collection sir } \\
\text { At diagnosis } \\
\text { I-year follow-up } \\
\text { 3-year follow-up }\end{array}$ & nce May 2011 \\
\hline Treatment variables & $\begin{array}{l}\text { Oncology } \\
\text { Surgery } \\
\text { Radiation therapy } \\
\text { Endocrine treatme }\end{array}$ & \\
\hline Pathology variables & $\begin{array}{l}\text { Gleason score } \\
\text { TNM stage }\end{array}$ & \\
\hline Laboratory variable & PSA at diagnosis & \\
\hline Comorbidity & $\mathrm{CCl}$ & \\
\hline variables $^{\mathrm{a}}$ & $\begin{array}{l}0=\text { none } \\
I=\text { low } \\
2=\text { medium } \\
3=\text { high }\end{array}$ & \\
\hline $\begin{array}{l}\text { Administrative } \\
\text { variables }\end{array}$ & $\begin{array}{l}\text { Region } \\
\text { Hospital site } \\
\text { Department }\end{array}$ & \\
\hline
\end{tabular}

Note: ${ }^{\text {a }} \mathrm{CCl}$ scores are systematically added to DAPROCAdata during conversion to the DNKK.

Abbreviations: $\mathrm{CCl}$, Charlson Comorbidity Index; DAPROCAdata, Danish Prostate Cancer Database; DNKK, Danish National Cancer Clinical Database; PROM, patient-reported outcome measures; PSA, prostate-specific antigen; TNM, tumor, node, and metastasis cancer stage classification.

specifically, the purpose of DAPROCAdata is to systematically collect key clinical parameters on all patients with incident prostate cancer in Denmark for health care monitoring, quality improvement, and research.

\section{Study population}

DAPROCAdata has collected data on all incident, histologically verified prostate cancer cases in Denmark since February 2010 and as of April 2015, a total of 22,332 patients were registered in the database (Table 2). The inclusion criteria are registration in the Danish Pathology Registry ${ }^{2}$ with either: 1) SNOMED codes T77x (prostate and seminal vesicles) and M8xxx3 (all malignant invasive neoplasms in the prostate) or 2) SNOMED codes $Æ F 4620$ (metastases originating from the
Table 2 Summary of patient population (patients diagnosed in the period from 2010 to April 2015) in DAPROCAdata by treatment group

\begin{tabular}{|c|c|}
\hline Treatment groups & Number $(\mathbf{N})^{a}$ \\
\hline \multirow{7}{*}{$\begin{array}{l}\text { Total number of patients with } \\
\text { prostate cancer registered in } \\
\text { DAPROCAdata }\end{array}$} & $\mathrm{N}=22,332$ (2010 to April 20I5) \\
\hline & $\mathrm{N}=4,077(2010)$ \\
\hline & $\mathrm{N}=4,229(201 \mathrm{I})$ \\
\hline & $N=4,279(2012)$ \\
\hline & $\mathrm{N}=4,252(2013)$ \\
\hline & $\mathrm{N}=4,58 \mathrm{I}(20 \mid 4)$ \\
\hline & $\mathrm{N}=914$ (January 2015 to April 2015) \\
\hline Patients with prostatectomy & $\mathrm{N}=4,795$ \\
\hline Patients with radiotherapy & $\mathrm{N}=6,1$ | 8 (total) \\
\hline Curative intent & $\mathrm{N}=3,324$ \\
\hline Palliative intent & $\mathrm{N}=2,794$ \\
\hline Patients with endocrine therapy & $\mathrm{N}=7,628$ \\
\hline $\begin{array}{l}\text { Patients with registered history of } \\
\text { chemotherapy }\end{array}$ & $\mathrm{N}=508$ \\
\hline $\begin{array}{l}\text { Patients registered with active } \\
\text { surveillance (based on the }\end{array}$ & $\mathrm{N}=2,327$ \\
\hline DAPROCA Urology Clinical Data & \\
\hline Registration Form) & \\
\hline
\end{tabular}

Note: ${ }^{2}$ Data (as of April 2015) from the DAPROCAdata 2014 Annual Report. ${ }^{6}$ Abbreviations: DAPROCAdata, Danish Prostate Cancer Database; DAPROCA, Danish Prostate Cancer Group.

prostate). The exclusion criteria are: 1) inconclusive prostate cancer diagnosis (eg, a relevant M-code registered together with the diagnosis code ÆYYY00, “obs. pro”); 2) patients with temporary personal identification numbers (ie, nonpermanent residents); and 3) patients diagnosed in relation to having undergone cystectomy (surgical codes: KKCC10, KKCC11, KKCC20, KKCC21).

\section{Main variables}

Clinical data and selected characteristics for patients with prostate cancer at the time of diagnosis are systematically recorded in DAPROCAdata by a combination of automatized linkage to nationwide health registries (eg, the Danish Pathology Registry, the Danish National Patient Register, ${ }^{3}$ and the Civil Registration System ${ }^{4}$ ) and online registration of key clinical parameters by treating clinicians at the surgical and oncological departments.

Diagnostic and tumor characteristics are retrieved from the Danish Pathology Registry (eg, histological verification, Gleason score, and TNM staging). Supplementary data are obtained from the Danish National Patient Register (eg, medical history and previous surgical procedures prior to prostate cancer). Data on vital status and migration are obtained from the Civil Registration System. ${ }^{4}$ Furthermore, an ongoing medical record validation study evaluates the feasibility of including data on cause-specific death from the Danish 
Table 3 Clinical quality indicators in DAPROCAdata (year 2014)

\begin{tabular}{|c|c|c|c|}
\hline Indicator & Description of indicator & $\begin{array}{l}\text { Type of } \\
\text { indicator }\end{array}$ & Standard ${ }^{a}$ \\
\hline $\begin{array}{l}\text { Indicator I: hospital admission after } \\
\text { TRUS }\end{array}$ & Proportion of patients admitted after TRUS-guided biopsy & Process & $<5 \%$ \\
\hline $\begin{array}{l}\text { Indicator 2a: active surveillance after } \\
\text { I year }\end{array}$ & $\begin{array}{l}\text { Proportion of patients under "active surveillance" without events } \\
\text { after I year }\end{array}$ & Process & $>70 \%$ \\
\hline $\begin{array}{l}\text { Indicator } 2 \mathrm{~b} \text { : active surveillance after } \\
3 \text { years }\end{array}$ & $\begin{array}{l}\text { Proportion of patients under "active surveillance" without events } \\
\text { after } 3 \text { years }\end{array}$ & Process & $>50 \%$ \\
\hline $\begin{array}{l}\text { Indicator 3: positive surgical } \\
\text { margin (pT2) }\end{array}$ & Proportion of RP patients ( $\mathrm{PT} 2$ ) with positive surgical margins & Result & $<25 \%$ \\
\hline $\begin{array}{l}\text { Indicator } 4: \text { positive surgical } \\
\text { margin (pT3) }\end{array}$ & Proportion of RP patients ( $\mathrm{pT} 3$ ) with positive surgical margins & Result & $<40 \%$ \\
\hline Indicator 5: postoperative morbidity & Proportion of patients with postoperative admission $>3$ days & Result & $<5 \%$ \\
\hline Indicator 6: 30-day morbidity & $\begin{array}{l}\text { Proportion of patients readmitted with complications }<30 \text { days } \\
\text { after RP operation }\end{array}$ & Result & $<5 \%$ \\
\hline Indicator 7a: I-year morbidity & $\begin{array}{l}\text { Proportion of RP patients with any hospital admission }>30 \text { days } \\
\text { and }<\text { I year after operation }\end{array}$ & Result & $\begin{array}{l}\text { Not } \\
\text { defined }\end{array}$ \\
\hline Indicator 7b: I-year morbidity & $\begin{array}{l}\text { Proportion of RP patients with any hospital admission }>30 \text { days } \\
\text { and }<\text { I year after radiation therapy }\end{array}$ & Result & $\begin{array}{l}\text { Not } \\
\text { defined }\end{array}$ \\
\hline Indicator 8: I-year mortality & Proportion of RP patients deceased $<\mathrm{I}$ year after operation & Result & $<1 \%$ \\
\hline $\begin{array}{l}\text { Indicator 9a: endocrine treatment } \\
\text { for } \mathrm{TI} / \mathrm{T} 2\end{array}$ & $\begin{array}{l}\text { Proportion of patients with TI/T2 disease }(<\mathrm{T} 3 ; \mathrm{No} / \mathrm{Nx} \text {; } \\
\text { Mo/Mx; PSA }<40) \text { receiving endocrine treatment }<6 \text { months } \\
\text { after diagnosis }(\mathrm{M}+)\end{array}$ & Process & $<25 \%$ \\
\hline $\begin{array}{l}\text { Indicator 9b: endocrine treatment } \\
\text { for } \mathrm{NI}\end{array}$ & $\begin{array}{l}\text { Proportion of patients with } \mathrm{NI} \text { stage }(\mathrm{NI} ; \mathrm{Mo} / \mathrm{Mx} / \text { Missing } \mathrm{M}) \\
\text { receiving endocrine treatment }<6 \text { months after diagnosis }\end{array}$ & Process & $>75 \%$ \\
\hline $\begin{array}{l}\text { Indicator 9c: endocrine treatment } \\
\text { for } \mathrm{MI}\end{array}$ & $\begin{array}{l}\text { Proportion of patients with metastases }(\mathrm{MI}) \text { receiving endocrine } \\
\text { treatment }<6 \text { months after diagnosis }(<\mathrm{T} 3 \mathrm{No} \text {; Nx; Mo; } \mathrm{Mx} \text {; } \\
\text { PSA }<40)\end{array}$ & Process & $>75 \%$ \\
\hline Indicator 10a: data completeness & $\begin{array}{l}\text { Proportion of diagnosed patients with PSA, cardinal symptoms, } \\
\text { and cTNM variables registered in the DAPROCA - Diagnosis } \\
\text { Clinical Data Registration Form }\end{array}$ & Result & $>90 \%$ \\
\hline Indicator I0b: data completeness & $\begin{array}{l}\text { Proportion of RP patients with registration of treatment history } \\
\text { in the DAPROCA - Urology Clinical Data Registration Form }\end{array}$ & Result & $>80 \%$ \\
\hline Indicator I0c: Data completeness & $\begin{array}{l}\text { Proportion of patients receiving curative radiotherapy and with } \\
\text { a registration of the date of clinical decision making in the } \\
\text { DAPROCA - Oncology Clinical Data Registration Form }\end{array}$ & Result & $>90 \%$ \\
\hline Indicator I0d: data completeness & Proportion of patients with completed PROM questionnaires & Result & $>80 \%$ \\
\hline
\end{tabular}

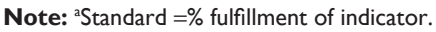

Abbreviations: DAPROCAdata, Danish Prostate Cancer Database; DAPROCA, Danish Prostate Cancer Group; PROM, patient-reported outcome measures; PSA, prostate-specific antigen; RP, radical prostatectomy; TRUS, transrectal ultrasound; TNM, tumor, node, and metastasis cancer stage classification.

Causes of Death Registry ${ }^{5}$ in DAPROCAdata. Key data related to the index prostate cancer diagnosis are registered by physicians at the treating urological and oncological centers using a specifically developed online registration system. These data include prostate-specific antigen values, prostate cancer-related surgical procedures, and oncological therapy. Separate data registration forms are used for the collection of data at the time of diagnosis and for subsequent urological and oncological information.

A key feature of DAPROCAdata is the routine collection of patient-reported outcome measures (PROM) since 2011. Patient questionnaires recording adverse effects following treatment and general quality-of-life aspects are collected at diagnosis, and at 1-year and 3-year follow-up.
In 2014, the completeness of PROM questionnaire data from all newly diagnosed patients was only $26 \%$; however, the response proportion at 1-year follow-up among those selected to participate in the initial survey was high $(92 \%){ }^{6}$ In addition to quality-of-life measurements (eg, pain levels, physical activity, sexual function, depression, urine and fecal incontinence), the PROM questionnaires also collect data on lifestyle factors such as smoking, alcohol consumption, and body mass index.

In 2014, the completeness of online clinical registrations reached $70 \%{ }^{6}$ In addition, in 2014 , ten clinical quality indicators were defined by the DAPROCAdata Steering Committee with the aim of improving quality assessment related to the diagnosis, treatment, and recurrence of prostate cancer in 
Denmark. The DAPROCAdata Steering Committee regularly evaluates the clinical relevance and utility of the clinical quality indicators in an ongoing effort toward continued refinement and quality improvement. Table 3 summarizes the clinical quality indicators and standards defined in 2014.

\section{Follow-up}

DAPROCAdata has complete follow-up on all registered patients with prostate cancer. All patients are followed from the date of inclusion in DAPROCAdata (ie, the date of cancer diagnosis) until death or emigration. This is possible by means of automatized linkage to the Danish Civil Registration System for information on vital status and residency.

\section{Examples of research}

Since its establishment in 2010, DAPROCAdata has created the basis for annual quality improvement reports with detailed analyses of the clinical quality indicators. ${ }^{6}$ As the clinical database is young, the data presented in the existing annual reports should be interpreted with caution and especially reports from the very first years after establishment. Data completeness was low during the first year and not all relevant clinical departments participated in online data registration from the start. Nevertheless, the annual reports for the first 5 years document that data validity and completeness have steadily improved, as has the performance of the clinical quality indicators against the predefined set of quality indicator standards (Table 3).

Several validation and epidemiological studies based on data from the initial 5 years of follow-up from 2010 to 2014 are in progress (data not published). DAPROCAdata will also participate in the DMCG.dk Benchmarking Consortium ${ }^{7}$ with planned benchmarking analyses on survival and mortality.

\section{Administration and funding}

DAPROCAdata is under the auspices of the Danish Multidisciplinary Cancer Groups (DMCG.dk), which is an umbrella organization comprised of 24 national, diseasespecific cancer groups and clinical databases. ${ }^{8}$ The urological cancer groups and databases are further organized under the Danish Urological Cancer Group. ${ }^{9}$ DAPROCAdata is funded by the Danish Regions ${ }^{10}$ and is administered by the Danish Clinical Registries (RKKP). ${ }^{11}$ Technical support and data management is provided by the Registry Support Centre for Clinical Quality and Health Informatics (KCKS-Vest). ${ }^{12}$ Epidemiological and statistical support in the preparation of annual reports is provided by the Registry Support Centre for Epidemiology and Biostatistics, North (KCEB-Nord). ${ }^{13}$ The nationwide collection of PROM data at all urologic and oncologic centers in Denmark is performed in collaboration with WestChronic. ${ }^{14,15}$ In 2015, the Danish Cancer Society collaborated with DAPROCA and WestChronic in a 1-year parallel project on PROM data from prostate cancer patients, but restricted to five participating centers.

The DAPROCAdata Steering Committee is comprised of clinicians and academic experts representing urology, oncology, pathology, epidemiology, biostatistics, and quality improvement science. In addition to ongoing refinement of the clinical quality indicators and the publication of annual reports, the Steering Committee promotes initiatives to improve data completeness, validity, and coding practices.

Data are collected in accordance with current Danish data protection laws (Sundhedslovens $\S 196$, stk 4 - law nr 546, dated June 24, 2005/law nr 603, dated June 18, 2012). Laws and procedures for data access to DAPROCAdata are governed by the Data Protection Agency (Datatilsynet) and the National Board of Health (Sundhedsstyrelsen). Applications for access to DAPROCAdata are reviewed by the Chair and Steering Committee following application to RKKP.

\section{Conclusion}

DAPROCAdata was established in 2010 and is, thus, a relatively young clinical database. Efforts to improve data collection, data validity, and data completeness are ongoing and of high priority. Updated information on DAPROCAdata is available at DAPROCA's internet homepage: http://ducg.dk/daproca-prostatacancer/.

\section{Acknowledgments}

This paper was funded by the Program for Clinical Research Infrastructure established by the Lundbeck Foundation and the Novo Nordisk Foundation and administered by the Danish Regions.

\section{Disclosure}

MNN is funded by The Movember Foundation. The authors report no other conflicts of interest in this work.

\section{References}

1. Borre M, Høyer M, Friis S, et al. DaProCadata - Dansk Prostatacancer Database (in Danish). Ugeskrift for Laeger. 2012;174(42):2556.

2. Bjerregaard B, Larsen OB. The Danish pathology register. Scand J Public Health. 2011;39(7 suppl):72-74.

3. Lynge E, Sandegaard JL, Rebolj M. The Danish national patient register. Scand J Public Health. 2011;39(7 suppl):30-33.

4. Pedersen CB. The Danish civil registration system. Scand J Public Health. 2011;39(7 suppl):22-25. 
5. Helweg-Larsen K. The Danish register of causes of death. Scand J Public Health. 2011;39(7 suppl):26-29.

6. DAPROCAdata [webpage on the internet]. Annual Report (in Danish). 2014. Available from: https://www.sundhed.dk/content/cms/86/15686_ daproca_årsrapport-2014_kommenteret_20150521final.pdf. Accessed December 23, 2015.

7. DMCG.dk Benchmarking Consortium [homepage on the internet]. Available from: http://dmcg.dk/dmcgdk-benchmarking-consortium/. Accessed December 23, 2015.

8. Danish Multidisciplinary Cancer Groups (DMCG.dk) [homepage on the internet]. Available from: http://dmcg.dk/. Accessed December 23, 2015.

9. Danish Urological Cancer Groups (DUCG) [homepage on the internet]. Available from: http://ducg.dk/. Accessed December 23, 2015.

10. Danish Regions [homepage on the internet]. Available from: http:// www.regioner.dk/. Accessed December 23, 2015.
11. Danish Clinical Registries (RKKP) [homepage on the internet]. Available from: http://www.rkkp.dk/. Accessed December 23, 2015.

12. Registry Support Centre for Clinical Quality and Health Informatics (KSKS-Vest) [webpage on the internet]. Available from: http://www. kcks-vest.dk/kliniske-kvalitetsdatabaser/prostata-cancer/. Accessed December 23, 2015.

13. Registry Support Centre for Epidemiology and Biostatistics, North (KCEB-Nord) [webpage on the internet]. Available from: http:// www.kea.au.dk/en/ClinicalQuality/CentreClinEpiBiostatNorth.html. Accessed December 23, 2015.

14. Hjollund NHI, Larsen LP, Biering K, Johnsen SP, Riiskjær E, Schougaard LM. Use of patient-reported outcome (PRO) measures at group and patient levels: experiences from the generic integrated PRO system, WestChronic. Interact J Med Res. 2014;3(1):e5.

15. WestChronic [Vestkronik-AmbuFlex] [homepage on the internet]. Available from: http://info.ambuflex.dk/. Accessed December 23, 2015.
Clinical Epidemiology

\section{Publish your work in this journal}

Clinical Epidemiology is an international, peer-reviewed, open access, online journal focusing on disease and drug epidemiology, identification of risk factors and screening procedures to develop optimal preventative initiatives and programs. Specific topics include: diagnosis, prognosis, treatment, screening, prevention, risk factor modification,

Submit your manuscript here: http://www.dovepress.com/clinical-epidemiology-journal

\section{Dovepress}

systematic reviews, risk \& safety of medical interventions, epidemiology \& biostatistical methods, and evaluation of guidelines, translational medicine, health policies \& economic evaluations. The manuscript management system is completely online and includes a very quick and fair peer-review system, which is all easy to use. 